\title{
Criteria of a cognitive concept of objectivity for use in social insurance medicine
}

Hans Magnus Solli', António Barbosa da Silva²

'Objective finding' is the traditional medical criterion for objectivity. In many cases in social insurance medicine, however, no objective findings are present. An issue, therefore, arises about additional criteria of objectivity that also could supplement objective findings regarding embodied subjects. We reviewed concepts of objectivity and subjectivity from a philosophical perspective to clear the ground for a conception of the embodied human being and a comprehensive cognitive concept of objectivity (CCCO). The fundamental assumption for the fruitful use of this concept is that descriptions, assessments and use of professional models should be based on reasons to apply the concept. The concept also presupposes genuine communication between the claimant of social insurance and the social insurance medicine professional. It is noteworthy that cognitive objectivity occurs in degrees, i.e., a professional can be more or less objective. On this basis, we defined a CCCO that can be used in health care and social insurance medicine according to four necessary conditions. We specified the corresponding criteria for its application and tested its usefulness in work disability assessments in medical certificates. This article aims to describe the four criteria of cognitive objectivity for application in social insurance medicine.

\section{Methods \\ Philosophical analysis and qualitative interpretation of 18 disability assessments from a total of 86 medical certifi- cates from hospital-based mental health care, regarded as texts. \\ Results \\ The purpose of the first three criteria is to ensure a de- scription and interpretation of the claimant as an individ- ual embodied person. The first criterion characterises the scope of a claimant's situation. A description should start where the 2001 International Classification of Function- ing, Disability and Health of the World Health Organisa- tion (WHO's ICF) also starts: the claimant as an acting, participating individual in a physical environment and in a social context. ${ }^{1}$ The claimant's first-person perspective should be recognised.}

Research Unit, Division of Mental Health and Addiction, Vestfold Hospital Trust, Tønsberg, Norway

${ }^{2}$ Ansgar University College and Theological Seminary, Kristiansand, Norway

Author for correspondence:

hmsolli@online.no
The second criterion characterises the descriptions. Different kinds of meaningful data about the person and his/her situation should be taken into account. We grouped the data into standard clinical data, psychometric data and behavioural data. Concerning behavioural data, the ICF provides concepts to describe human functioning in three dimensions. ${ }^{1}$ The claimants' expressions regarding their personal world, e.g., social relations, and their reflections on future goals can be essential data in social insurance medicine.

The third criterion characterises interpretations. A professional has to reasonably interpret all the data mentioned above in terms of professional models of disease, health, and work ability and disability and should do this in the context of assessment. Traditionally, objective finding was defined in terms of absolute reality found by a pathologist, or surgeon, or shown by laboratory tests. According to the CCCO, the data from various clinical tests are valid, but the significance in the actual context has to be established by interpretation. Cognitively, objective finding is one of the criteria of objectivity.

The fourth criterion consists of applying cognitive principles that are general and well known in various disciplines. The first principle is professional expertise (German Sachlichkeit). Professionality means that an account should be built upon available facts/data and be supported by arguments. Other principles are impartiality, accuracy, correctness and dialogical intersubjectivity. We used the criteria to understand why objectivity fails in the context of work disability assessment and how it can be improved or safeguarded.

\section{Conclusion}

The article specifies four criteria of cognitive objectivity in social insurance medicine. According to these criteria, cognitive objective finding is one of the criteria of objectivity.

Original publication: Solli HM, Barbosa da Silva A. Objectivity applied to embodied subjects in health care and social security medicine: definition of a comprehensive concept of cognitive objectivity and criteria for its application. BMC Medical Ethics 2018. https://doi.org/10.1186/s12910-018-0254-9.

\section{Reference}

1. WHO. International Classification of Functioning, Disability and Health: ICF. Geneva: WHO; 2001. 